\title{
Endoscopic Bariatric/Metabolic Surgery
}

\author{
Daanish Kazi, DO ${ }^{1}$ Leena Khaitan, MD, MPH, FASMBS ${ }^{1}$ \\ ${ }^{1}$ University Hospitals, Cleveland Medical Center, Cleveland, Ohio \\ Address for correspondence Leena Khaitan, MD, MPH, FASMBS, \\ 11100 Euclid Avenue, Cleveland, OH 44106 \\ Dig Dis Interv 2018;2:375-382. \\ (e-mail: leena.khaitan@uhhospitals.org).
}

\begin{abstract}
Keywords

- bariatric endoscopy

- balloon

- endoscopic sleeve

- endoscopic weight loss procedures

Endoscopic approaches to the bariatric patient have increased significantly in the last two decades. Obese patients present a challenge to surgeons as they are at higher risk of having perioperative complications. Patients also are seeking less and less invasive ways to have procedures performed. The combination of these two demands has led to the development of new technologies in the bariatric arena. Now there are several new endoscopic approaches for primary weight loss. Endoscopic metabolic procedures are developing for the management of diabetes. This article reviews the latest in these technologies.
\end{abstract}

Obesity is a healthcare crisis that is impacting cost and patient care in the United States. The core components of any weight loss program are diet and exercise, but multiple studies have shown that this is not a durable approach for many patients, especially those in obesity Class 2 and higher. The most durable weight loss approaches described are surgical and include procedures that are restrictive, malabsorptive, or both. In between the two extremes, there is a gap in weight loss management. This is where medications and endoscopic approaches to obesity fit in. Medications for weight loss will not be discussed in this article.

Endoscopic approaches are attractive to the patient because they are less invasive and less anatomically altering than surgical procedures. These procedures are attractive to referring physicians as these are perceived as less invasive and therefore carry less risk. For the interventional endoscopist, these procedures are technically challenging but very rewarding when the patient has successful weight loss. Endoscopic procedures are perceived as better for poor surgical candidates who need staging procedure to tolerate surgery super obese or those who are at the borderline of becoming obese. Emerging treatments also may help those who are normal weight but require help with glycemic control. ${ }^{1}$

For the last several decades, many endoscopic procedures have been attempted. These procedures follow the same principles as surgical approaches in that they are restrictive or malabsorptive. In the restrictive category, options include intragastric space occupying devices and sutures/staples to limit gastric capacity. These procedures work by limiting the capacity of food, creating satiety by using stretch receptors at

received

September 26, 2018

accepted

October 4, 2018

published online

December 10, 2018 the antrum, or reducing gastric emptying. The malabsorptive procedures include implantable sleeves, ablative techniques, and endoscopic anastomoses created by magnets. Many of these procedures are considered metabolic procedures that may provide new ways to treat diabetes. This article will review the latest technologies in all of these arenas.

\section{Primary Endoscopic Weight Loss Procedures}

\section{Space-Occupying Devices}

One of the first endoscopic devices for weight loss was the Garren-Edwards Gastric Bubble, developed in the 1980. This was considered ground breaking at the time until this had complications including deflations that required surgical interventions, gastric ulcers, and patient intolerance. This device was removed from the market due to these serious complications and ineffective weight loss. These devices were then absent from the US market for years while they gained momentum in Europe. ${ }^{2}$ Now there are currently three space filling devices that are US Food and Drug Administration (FDA) approved within the United States-Orbera, Reshape, and Obalon. The first two are fluid filled, while the last is air filled.

\section{Fluid-Filled Balloons}

\section{Orbera}

Orbera (Bioenterics Intragastric Baloon (BIB), Apollo Endosurgery Inc., Austin, TX) is the first of these devices to be FDA approved in August of 2015. The fluid-filled single balloon is
Copyright $\odot 2018$ by Thieme Medical Publishers, Inc., 333 Seventh Avenue, New York, NY 10001, USA Tel: +1(212) 584-4662.
DOI https://doi.org/ 10.1055/s-0038-1675593. ISSN 2472-8721.
Guest Editor, Kevin El-Hayek, MD 
placed and removed endoscopically under sedation after 6 months of implantation. The device is introduced by mouth, placed within the stomach, and inflated with saline from 500 to $700 \mathrm{~mL}$ to a grapefruit size volume $(\sim 10 \mathrm{~cm})$ under direct endoscopic visualization. The device is made of a silicone polymer and is resistant to acid. Contraindications include gastroparesis, hiatal hernia, large ulcers, or prior gastric surgery. ${ }^{1-6}$

The first large series of Orbera device placements in Spain reported an excess weight loss (EWL) of $33.9 \pm 18.7 \%$. The authors noted diabetes resolution or improvement in $86.9 \%$ and hypertension improvement or resolution in $93.7 \%$ of patients. Their complication rate was low at $2.8 \%$, but included perforation and death. ${ }^{4}$ Dastis et al demonstrated that longterm weight loss can be maintained out to 2 and $1 / 2$ in 100 individuals who had the balloon for only 6 months. Many studies all showed successful weight loss that is maintained if the patient is compliant and behavior change is initiated in the early stages of treatment. ${ }^{7}$ One of the largest series to date of the Orbera balloon is the Brazilian consensus statement of 40,000 balloons, of which $\sim 32,000$ were the Orbera. The mean percentage of total weight loss (TWL) was $18.4 \pm 2.9 \%$. Patients lost a mean of $18.3 \pm 4.4 \mathrm{~kg}$. The failure rate (defined as percentage of TWL $<10 \%$ ) was only $8.3 \pm 6.7 \%$. The statement provides a guide reflective of large clinical experience on how to perform the procedures, manage patient nausea symptoms, and manage ongoing care of patients. Of note, the data in this study shows better weight loss than most studies with the balloon. ${ }^{8}$

\section{Reshape}

The Reshape Duo uses two balloons attached in tandem allowing for higher filling volumes from 750 to $900 \mathrm{~mL}$ of saline. It takes up more of the stomach volume compared with a single balloon, avoids over distention, and conforms to the natural curve of the stomach for patient comfort and tolerability. This balloon is implanted endoscopically and removed the same way 6 months later. The other advantage stated is that if one balloon deflates, the other will remain inflated, thereby reducing migration. The REDUCE trial concluded that 55\% of patients (mean body mass index [BMI] 45.4) with the balloon lost an average of $25.1 \%$ excess body weight within 6 months compared with only $6 \%$ with diet and exercise alone. Adverse events reported were balloon deflation in $6 \%$ of patients with no migrations, and gastric ulcers in $10 \%$ of patients. ${ }^{9}$ Other series with this balloon are limited.

Currently, there are several fluid-filled balloons in development and trials.

\section{Spatz Balloon}

The Spatz Adjustable Balloon System (Spatz Medical, NY) has an attached anchor and a valve to adjust the volume. This allows the physician to manage early intolerance by adjusting the volume of the balloon between 400 and $800 \mathrm{~mL}$, and then to increase volume as weight loss plateaus. The Spatz balloon is intended for 12 months implantation and is currently being used outside the United States. Issues with the Spatz balloon include deflation leading to the need for surgical extraction. ${ }^{4}$ The adjustable nature of this balloon and the longer implant time make this device more attractive than the other balloons. It is not yet FDA approved but is in multicenter trial in the United States.

\section{Devices No Longer Available}

The Silimed is a smooth transparent silicon shell with saline that is placed by endoscopic traction under direct visualization and rolled up inside a thin silicone sheath anchored to the tip of the endoscope with a snare. This is removed as an entire system held in an overtube device. The literature identifies this as being a safer technique done with direct visualization under conscious sedation. ${ }^{10}$ The Medsil balloon is saline filled with maximum volume of $700 \mathrm{~mL}$ placed similarly to the Orbera and Silimed. ${ }^{1,3}$ It is not offered in the United States but is available in Europe.

\section{Air- or Gas-Filled Balloons}

\section{Obalon}

The Obalon is the only FDA-approved gas-filled balloon. This device can be placed in the office as it is swallowed as a gel that sits at the end of thin tubing. Then the device is filled with a proprietary gas and checked for placement using fluoroscopy. Therefore, only one endoscopic procedure is required for removal. However, fluoroscopy is needed to verify placement, and therefore is an extra radiation exposure for the patient. Each balloon is $250 \mathrm{~mL}$ in volume of gas and up to three balloons are placed over a 6 to 12 weeks period if weight loss plateaus. This sequential addition of volume is thought to be better tolerated by patients with less nausea. The reported weight loss is $\sim 5 \mathrm{~kg}$ for patients. ${ }^{11}$

\section{Heliosphere}

The Heliosphere BAG is a double bag polymer balloon covered with silicon envelope placed for 6 months. It is filled with air, and is stated that it may reduce the risk of digestive intolerance as compared with fluid-filled balloons. The balloon has a high rate of system failure at positioning, spontaneous deflation, absence of marker, and large size with balloon that isn't compliant, and causes intolerance to patients. ${ }^{1,12}$

Elipse

The Elipse balloon (Elipse Balloon, Allurion Technologies, Natick, MA) is a very exciting new technology. This device does not require procedures for placement or removal. The Elipse balloon is swallowed in the office and the valve dissolves over time. Once the balloon deflates, it passes through the bowels and is not thought to be associated with bowel obstruction. Currently, this device is in clinical trials. A device such as this may revolutionize the nonsurgical approach to weight loss. Because no procedures are required, this allows several providers interested in weight management to have a new tool they may be able to offer their patients. The data so far is promising. An Italian study showed early results with mean \%EWL of $26 \%$ at 4 months. No problems with passage of the balloon were seen in these 38 patients. ${ }^{13}$ Another balloon in development is the Endoball. This device can be filled with both fluid and air between 500 and $800 \mathrm{~mL} .^{1,2}$ No data are available at this time. 


\section{Complications with the Balloons}

Balloons have recently come under fire as complications are coming to light. The FDA has cautioned against their use due to deaths that have been reported with the balloons. ${ }^{14}$ Pancreatitis, perforation, ulcer formation, rupture/deflation of device possibly leading to outlet obstruction or bowel obstruction, and bleeding are reported complications. The deaths have occurred primarily with fluid-filled balloons. A recent statement by Tate and Geliebter notes 33 deaths related to the Orbera and Reshape balloons since 2006. ${ }^{15}$ The FDA Web site can be visited for further information. Overall none of the deaths have resulted in removal of the devices from the market. However, they do caution the interventionalist to stay within the guidelines with regard to implantation time, attention to prior gastric procedures, compliance of the patient, large hiatal hernia, volume placed in the balloons, and BMI of the patient. Both ASMBS (American Society for Metabolic and Bariatric Surgery) and SAGES (Society of American Gastrointestinal and Endoscopic Surgeons) have issued statements stating the devices are safe if used within the guidelines. ${ }^{16}$

\section{Advantages of the Balloons}

The balloon can not only be used for primary weight loss procedures but also can be used as a bridge procedure to other weight loss surgeries. One of the uses is to decrease anesthetic risk in severely obese patients planning to undergo bariatric surgery by getting their BMI to a more operable weight. ${ }^{17}$ Zerrweck et al. looked at patients with BMI greater than $60 \mathrm{~kg} / \mathrm{m}^{2}$ who received balloons. These endoscopic procedures were associated with shorter operative time and lower overall risk of adverse outcomes as compared with surgery in this population. ${ }^{6}$

Unfortunately, this advantage of the balloon cannot be realized in the United States as it is only FDA approved for BMI 30 to 40. The balloons may also be helpful in those patients who need to lose weight but are poor surgical candidates due to prior surgeries or high anesthesia risks. Again in the United States, this would not be possible for BMIs over 40. In light of the recent FDA warnings, these offlabel uses should only be done in a study that is monitored by an institutional review board.

\section{Balloon Outcomes}

Most studies have shown fluid-filled balloons to have greater weight loss than the air-filled balloons ( - Table 1 ). A recent meta-analysis of all of the randomized trials utilizing balloons showed reasonable short-term weight loss; however, long-term weight efficacy was questioned. ${ }^{18}$ This study included trials with many different balloons. Other comparative studies have had similar findings. A network metaanalysis included 15 studies that noted superiority of fluidfilled balloons over the air-filled balloons in the short-term (6 and 12 months). ${ }^{19}$ Studies from Brazil and Spain have had more promising results. The Brazilian consensus study has

Table 1 Intragastric balloons: Basic facts regarding implantation time, method of placement, and removal and availability in the United States

\begin{tabular}{|c|c|c|c|}
\hline Balloon and composition & FDA approval/Indications & $\begin{array}{l}\text { Approved typical time for } \\
\text { implantation }\end{array}$ & $\begin{array}{l}\text { Placement and retrieval } \\
\text { method }\end{array}$ \\
\hline $\begin{array}{l}\text { Orbera (BIB) } \\
\text { Apollo Endosurgery } \\
\text { Silicone sphere filled with } \\
400-700 \mathrm{~mL} \text { of saline with } \\
\text { methylene blue solution }\end{array}$ & $\begin{array}{l}\text { FDA approved } \\
\text { BMI } 30-40 \mathrm{~km} / \mathrm{m}^{2} \\
\text { Age } \geq 20\end{array}$ & 6 months & $\begin{array}{l}\text { Placed and removed with } \\
\text { endoscopy }\end{array}$ \\
\hline $\begin{array}{l}\text { Reshape-integrated dual } \\
\text { balloon system Reshape } \\
\text { Medical } \\
\text { Two silicone spheres attached } \\
\text { in tandem, each filled with } \\
375-450 \mathrm{~mL} \text { of saline with } \\
\text { methylene blue solution }\end{array}$ & $\begin{array}{l}\text { FDA approved } \\
\text { BMI } 30-40 \mathrm{~km} / \mathrm{m}^{2} \text { and single } \\
\text { obesity related comorbidity } \\
\text { Age } 22-60\end{array}$ & 6 months & $\begin{array}{l}\text { Endoscopic placement and } \\
\text { removal }\end{array}$ \\
\hline $\begin{array}{l}\text { Obalon Balloon System Obalon } \\
\text { Therapeutics } \\
\text { Up to } 3 \text { separate sphere plastic } \\
\text { polymer filled with } 250 \mathrm{~mL} \text { of } \\
\text { inert gas }\end{array}$ & $\begin{array}{l}\text { FDA approved } \\
\text { BMI } 30-40 \mathrm{~km} / \mathrm{m}^{2} \\
\text { Age } \geq 20\end{array}$ & 6 months & $\begin{array}{l}3 \text { balloons placed in } 1 \text { month } \\
\text { increment (within } 12 \text { weeks) by } \\
\text { swallowing capsule under } \\
\text { fluoroscopy. Removed with } \\
\text { endoscopy }\end{array}$ \\
\hline $\begin{array}{l}\text { Elipse Balloon System } \\
\text { Allurion Technologies } \\
\text { Balloon sphere made of } \\
\text { proprietary film, filled with } \\
550 \mathrm{~mL} \text { of saline }\end{array}$ & Not FDA approved & 4 months & $\begin{array}{l}\text { Single balloon swallowed } \\
\text { under fluoroscopy. Valve } \\
\text { release in } 4 \text { months in situ and } \\
\text { passed via Gl tract when } \\
\text { deflated }\end{array}$ \\
\hline $\begin{array}{l}\text { Spatz Balloon System } \\
\text { Spatz FGIA } \\
\text { Saline filled silicone balloon } \\
\text { sphere with an attached } \\
\text { catheter to adjust fill volume } \\
\text { after implantation }\end{array}$ & Not FDA approved & 12 months & $\begin{array}{l}\text { Endoscopic placement, } \\
\text { adjustment, and removal }\end{array}$ \\
\hline
\end{tabular}

Abbreviations: BMI, body mass index; FDA, US Food and Drug Administration; GI, gastrointestinal. 
Table 2 Expected weight loss based on FDA-approved primary procedure

\begin{tabular}{|l|l|}
\hline $\begin{array}{l}\text { Type of primary } \\
\text { procedure }\end{array}$ & Weight loss \\
\hline Roux en Y gastric bypass & $70 \%$ excess body weight \\
\hline $\begin{array}{l}\text { Vertical sleeve } \\
\text { gastrectomy }\end{array}$ & $50 \%$ excess body weight \\
\hline Lap band & Up to 30\% excess body weight \\
\hline Balloon & $10 \%$ excess body weight \\
\hline $\begin{array}{l}\text { Endoscopic sleeve } \\
\text { gastroplasty }\end{array}$ & $20 \%$ excess body weight \\
\hline Aspire assist & $25-30 \%$ excess body weight \\
\hline
\end{tabular}

Abbreviation: FDA, US Food and Drug Administration.

raised some controversy regarding the results. ${ }^{20}$ This brings up the question of expectation. Should a balloon that is implanted for only 6 months be expected to have longterm efficacy, or should it be considered as an addition to the other weight management programs out there such as Jenny Craig and Weight Watchers? (-Table 2) The debate remains as to whether these devices will result in long-term weight loss. However, the short-term results are promising.

\section{Other Types of Space-Occupying Devices}

The concept for a semistationary antral balloon was first published in 2008. This is a pear-shaped silicone balloon $30 \mathrm{~cm}$ duodenal stem and $7 \mathrm{~g}$ metallic counter weight at the distal end. The conical end sits in the antrum and the distal weight utilizes peristalsis to come across the pylorus and anchor this device into place. The goal is to occlude the pylorus, intermittently prolong gastric emptying, and stimulate the satiety receptor. ${ }^{21}$ This has since evolved into the transpyloric shuttle which is endoscopically placed. It is a larger balloon, $\sim 56 \mathrm{~mm}$ in size, and sits in the stomach. The smaller balloon, $4 \mathrm{~mm} \times 96 \mathrm{~mm}$, is tethered to a small weight which sits in the duodenum. This allows for a normal peristalsis to help occlude the pylorus. Using this balloon, the Endobesity I trial showed weight loss without plateau on patients with mean BMI of 36. It showed in the 3 months cohort the mean \% EWL $31.3 \pm 15.7 \%$ and the mean weight loss of $8.9 \pm 5.2 \mathrm{~kg}$. In the 6 months cohort, they had \% EWL $50.0 \pm 26.4 \%$ and mean weight loss of $14.6 \pm 5.7 \mathrm{~kg}$. The device caused ulceration in two patients which resolved with removal. ${ }^{1-3}$ This is currently in trial in the United States.

\section{SatiSphere}

SatiSphere is endoscopically placed and is designed to delay transit time of nutrients through the duodenum. A $1-\mathrm{mm}$ nitinol wire with pigtail ends and several mesh spheres is mounted along its course from the gastric antrum to the duodenum to conform to the "c shape" loop of the duodenum. A small trial showed device migration in 10 out of 21 patients, two requiring emergency surgery, and this led to termination of the trial. The mechanism of weight loss is delayed glucose absorption and altered kinetics in glucagon-like peptide 1
(GLP-1) levels. Migrations in over 40\% of patients have kept this technology from being more widely explored. ${ }^{22}$

\section{Endoscopic Suturing Devices}

\section{Endoscopic Sleeve Gastroplasty}

Conceptually, these procedures have been in development for a long while. Endoscopically, sutures are placed so that the remaining lumen of the stomach emulates a vertical sleeve gastrectomy. One of the first endoscopic suturing devices was the Endocinch (Bard). This device was initially developed to treat gastroesophageal reflux disease and then was extended for suturing for weight loss. Fogel first showed weight loss results comparable to traditional bariatric procedures with up to $21.1 \% \mathrm{EWL}$ at 1 month, $39.6 \%$ EWL at 3 months, and 58.1\% EWL at 12 months of follow-up. The durability of the plications was in question due to plications not being full thickness. ${ }^{23}$

The Restore Suturing System by Davol/BARD has the ability to place deeper sutures without having to withdraw device for suture reloading. Transoral gastric volume reduction as an Intervention for Weight Management trial showed $27.7 \pm 21.9 \%$ EWL at 12 months follow-up. It requires an overtube and therefore intubation and general anesthesia. The procedure time is $\sim 45$ minutes. The EWL was $50 \%$ and less obese had a better response. ${ }^{24}$ This device is not yet FDA approved. Yet another independent platform is used for the Primary Obesity Surgery Endoluminal for tissue approximation and an endoscopic sleeved and is made by USGI Medical. This is still being studied.

The Overstitch device is the most successful device utilized for sutured gastroplasty and its use is increasing. The device is able to take full-thickness sutures and therefore is considered to place sutures that are more durable than the other devices mentioned. This device is FDA approved and is in widespread use among surgical endoscopists. A single center pilot study showed feasibility for endoscopic sleeve gastroplasty (ESG) with a running suture. Six to 12 stitches are placed in a triangular fashion at the anterior wall, greater curve, and posterior wall and started at the fundus. Since that study, most follow the modification by Kumar et al with suturing initiated at the antrum and running proximally toward the fundus. Interrupted sutures can be used to reinforce the sleeve. ${ }^{25}$ The BMI decrease was $34.242 \mathrm{~kg} / \mathrm{m}^{2}$ to 29.4 $42 \mathrm{~kg} / \mathrm{m}^{2}$ with mean weight loss of $13.1 \pm 1.3 \mathrm{~kg}$ after 1 year. More and more data are coming forth from around the world surrounding the ESG. A recent study combining data from the United States and Australia showed respectable weight loss. In total, 112 consecutive patients (male $31 \%$, age $45.1 \pm 11.7$ years, baseline BMI $37.9 \pm 6.7$ $\mathrm{kg} / \mathrm{m}^{2}$ ) underwent ESG. At 1, 3, and 6 months, change in weight was $9.0 \pm 4.6 \mathrm{~kg}$ (total body weight loss [TBWL] $8.4 \pm 4.1 \%$ ), $12.9 \pm 6.4 \mathrm{~kg}$ (TBWL $11.9 \pm 4.5 \%$ ), and $16.4 \pm 10.7 \mathrm{~kg}$ (TBWL $14.9 \pm 6.1 \%$ ), respectively. Adverse events were noted in $2.7 \%{ }^{26}$ 
When compared directly to sleeve gastrectomy in a case-matched study, the sleeve showed $6 \%$ more EWL with a higher incidence of new onset reflux. ${ }^{27}$

\section{Transoral Gastroplasty}

A device that is no longer available is the stapler for transoral gastroplasty (TOGA). A set of transoral flexible endoscopically guided staplers are used to create a gastric sleeve along the lesser curve of the stomach. The procedure requires two operators and a 60 Fr. Savory dilator. A flexible stapler is passed peroral in an over the wire technique. A 7 to $8 \mathrm{~cm}$ stapled apposition is made from the cardia to lesser curve and then followed distally. Adverse events within the first week included nausea, vomiting, pain, and transient dysphagia. The reported mean \% EWL were $16.2 \%$ at 1 month, $22.6 \%$ at 3 months, and $24.4 \%$ at 6 months. Gaps were noted in the staple line in 13 patients at 6 months follow-up on endoscopy. A second human trial with closer staple apposition and use of steroid and diclofenac had better results with a \% EWL at $19.2 \%$ at 1 month, $33.7 \%$ at 3 months, and $46 \%$ at 6 months. The TOGA trial by Familiari et al demonstrated safety and efficacy at 1 year. The mean starting BMI was 41.5 $\mathrm{kg} / \mathrm{m}^{2}$ and had a \% EWL of $29.3 \%$ at 3 months, $36.8 \%$ at 6 months, and $38.7 \%$ at 12 months. ${ }^{28}$ Minimal complications, such as respiratory insufficiency and an asymptomatic pneumoperitoneum, were reported and were treated conservatively. Staple line gaps incidence remained a problem; however, the gaps were reported to be small. Another limitation of the study was the variable weight loss counseling provided to the patients at the different sites. ${ }^{1,29}$ The technology was novel; however, the implementation of the procedure, surrounding counseling, and the expectation of equivalence to surgery may have been miscalculated.

\section{TransEndoscopic Restrictive Implants System}

TransEndoscopic Restrictive Implants System mimics the gastric band. With this device, a prosthetic diaphragm with a $10 \mathrm{~mm}$ orifice is stapled into the gastric cardia. This is designed to be permanent but can be easily removed or modified. The trial resulted in one patient with gastric perforation requiring surgery and removal of device, and two with pneumoperitoneum that could be managed nonoperatively. The \% EWL was $12.3 \%$ at 1 month and $22.2 \%$ at 3 months. $^{1,2}$ The high complication rate resulted in the device being returned to the design phase.

\section{Malabsorptive Endoluminal Procedures}

\section{EndoBarrier}

The duodenal jejunal bypass sleeve, The EndoBarrier (GI Dynamics, Lexington, MA), is one of the first endoluminal malabsorptive procedures introduced. The device was created to have malabsorption similar to that of the RouX-en-Y gastric bypass, with the primary goal of improving diabetes. A nitinol anchor sits in the duodenal bulb with a $60 \mathrm{~cm}$ fluoropolymer sleeve that prevents mixing of bile and pancreatic fluids with food, thereby limiting absorption in the proximal intestine. The theory is that the accelerated deliv- ery of chyme to the distal gastrointestinal tract allows for early release of GLP-1 and incretins which have roles in glycemic control and energy homeostasis. In theory, this should help with weight loss and control of type 2 diabetes mellitus. The first human trial involved 12 patients who were left implanted for 12 weeks. Mean \% EWL at 12 weeks was $23.6 \%$. Complications were two reports of a mucosal tear and an oropharyngeal mucosal tear not requiring intervention. Three of the four patients with diabetes mellitus were weaned off medications within 24 hours of implantation. He subsequently followed up his study looking closer at the hormonal effects and concluded the GLP- 1 is not affected. ${ }^{30}$

A second trial by Tarnoff et al compared the device (25 patients implanted) versus diet control (15 patients). Eighty percent of patients kept their implant in place for 12 weeks, and adverse events included gastrointestinal bleed, anchor migration, and stent obstruction. \%EWL at 12 weeks was $22 \%$ for device versus $5 \%$ for control. ${ }^{31,32}$ The early European experience has similar results. ${ }^{33}$ Multiple complications were noted in all of these trials including slippage (due to sharp angulation of the duodenum), mucosal tears, bleeding, liver abscess, cholangitis, cholecystitis, and esophageal perforation. ${ }^{33}$ Ultimately, the high incidence of liver abscesses in the US trial led to early termination of the trial and the device remains in redesign.

\section{ValenTx}

Gastroduodenojejunal bypass sleeve (ValenTx, Inc., Hopkins, $\mathrm{MN}$ ) is a sleeve anchored from gastroesophageal junction and extends from the proximal stomach into $120 \mathrm{~cm}$ of small bowel, thereby blocking absorption of food from the stomach to the jejunum. It mimics the malabsorptive properties of a gastric bypass. Post-procedural dysphagia is a common complication. The effectiveness of this procedure was first evaluated in 13 patients (mean BMI of $42 \mathrm{~kg} / \mathrm{m}^{2}$ ). The mean \% EWL was $54 \%$ for 10 patients who kept the implant for 1 year. Four patients with partial cuff detachment had less weight loss. Comorbidity improvement was noted with diabetes mellitus (DM), hypertension, hyperlipidemia, and use of DM medications. ${ }^{34}$

The device is currently in trials in the United States. The device has been placed mostly with a hybrid endoscopic and laparoscopic approach. A fully endoscopic approach is in development.

\section{Mucosal Resurfacing}

This technology is truly metabolic and involves ablation of the duodenal mucosa. The Revita DMR catheter (Fractyl, Lexington, MA) is passed into the duodenum under endoscopic visualization, and after a circumferential saline lift distal to the ampulla, a $2 \mathrm{~cm}$ balloon is inflated in the lumen. A burst of energy in the coils of the balloon ablated the surface of the duodenal mucosa. Ablation is performed to the desired length. Improved glycemic control is noted almost immediately with the theory of ablating diseased mucosa that will hopefully regenerate with normal mucosa. Adverse events include duodenal stenosis and abdominal pain. ${ }^{2,35}$ This technology is promising and is providing more insight into mechanisms of diabetes and obesity. 


\section{Aspiration Therapy}

Aspiration therapy is extremely controversial and has been likened to controlled bulimia. However, when the device and its success are examined closely, one can conclude that is a viable option for the right patient for weight management that can be controlled, not disruptive to a patient's chemistries and effective for ongoing weight loss. As opposed to other endoscopic weight loss techniques, this device is considered more durable as it can remain implanted in the stomach for an indefinite period of time. A gastrostomy tube

\section{Gastric Endoscopic Bariatric Therapies}

A
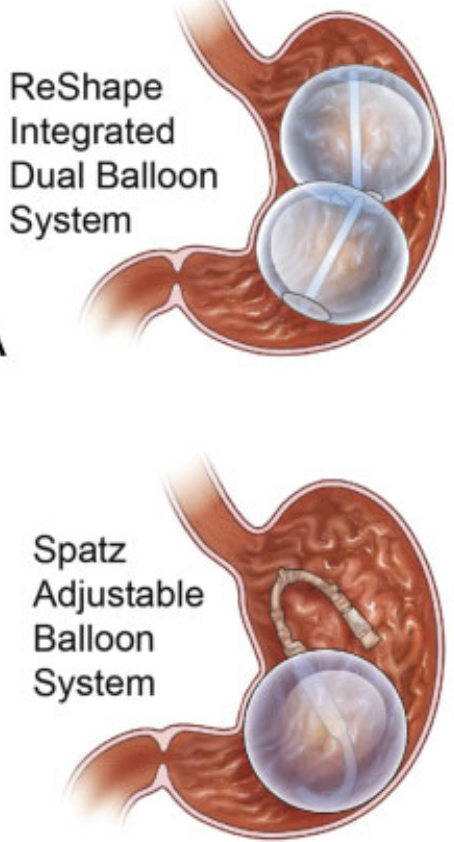

D

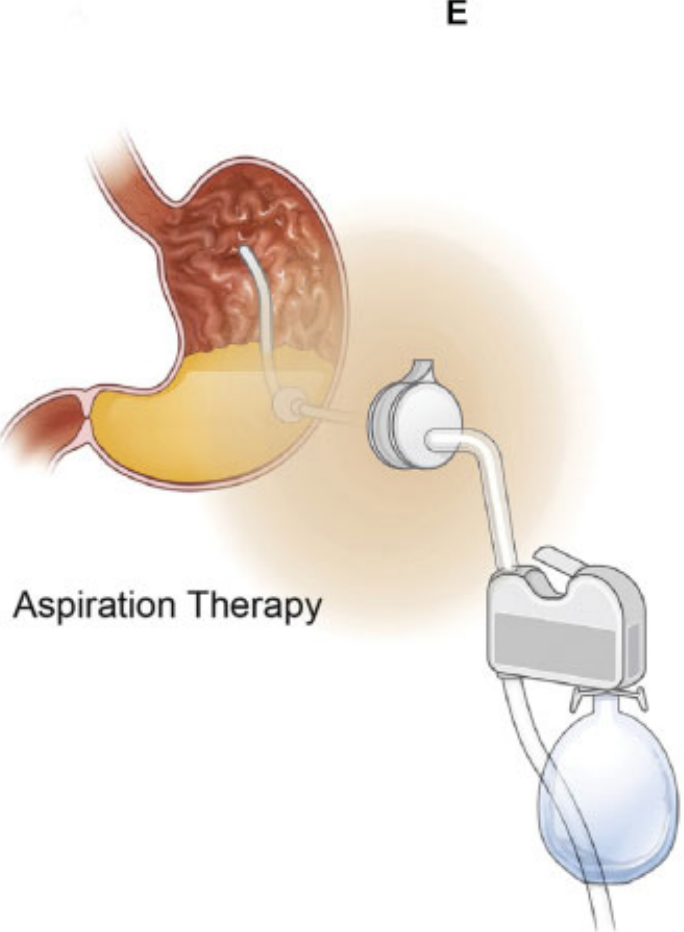



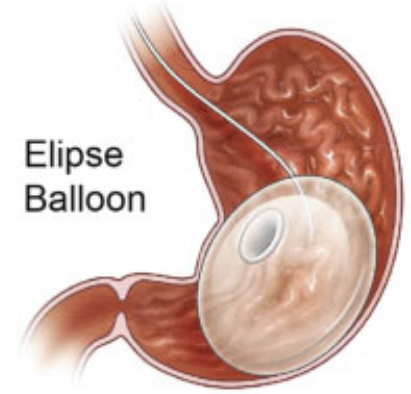

E

POSE

Procedure

H

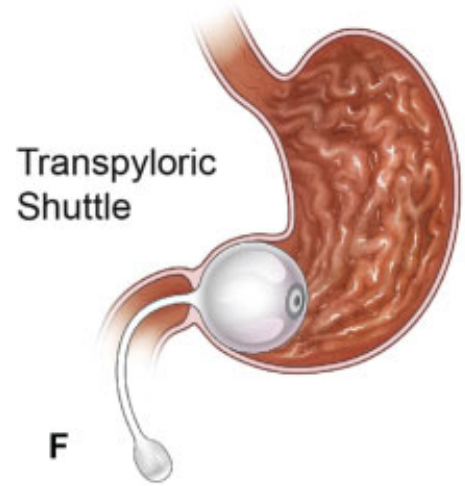


is placed traversing the abdominal wall from the lumen of the stomach to the surface of the skin. Patients are counseled on mindful eating. Then 20 minutes after eating, the patient syphons $30 \%$ of the stomach contents, leading to less caloric absorption and weight loss. Placement and removal are under conscious sedation with closure similar to a PEG tube. In a randomized trial for the treatment of Class 11 and Class 111 obesity, aspiration therapy was noted to be significantly more successful than lifestyle changes alone: AspireAssist groupwith $31.5 \pm 26.7$ of their excess body weight $(12.1 \pm 9.6$ total bodyweight), whereas those in the lifestyle counseling group had lost only a mean of $9.8 \pm 15.5$ of their excess body weight $(3.5 \pm 6.0$ total body weight) $(p<0.001) .{ }^{36}$ One of the longest longitudinal studies had 201 participants with 4 years follow-up. The starting BMI was $43.6 \pm 7.2 \mathrm{~kg} / \mathrm{m}^{2}$ and the mean \%TWL at $1,2,3$, and 4 years, respectively, was $18.2 \pm 9.4 \%, 19.8 \pm 11.3 \%$, $21.3 \pm 9.6 \%$, and $19.2 \pm 13.1 \%$. Clinically, significant reductions in glycated hemoglobin A1c (HbA1c), triglycerides, and blood pressure were observed. For participants with diabetes, HbA1c decreased by $1 \%(p<0.0001)$ from $7.8 \%$ at baseline to $6.8 \%$ at 1 year. ${ }^{37}$ Although FDA approved for years, the adoption of this therapy has been slow.

\section{Magnamosis}

Magnets are utilized to create intestinal anastomoses so that a gastric bypass can theoretically be performed endoscopically. These are self-assembling magnets that are placed using upper and lower endoscopy with fluoroscopic guidance for dual path enteral bypass in the small bowel (incisionless magnetic anastomosis system). Once the magnets connect, necrosis creates a fistula opening. Transient nausea and diarrhea were reported and resolved. A small study reported 10.6\% EWL at 6 months. ${ }^{2,38}$ This is currently undergoing evaluation in the United States but is not FDA approved.

\section{Full Sense Device}

The Full Sense Device is placed via endoscopy in the distal esophagus and proximal stomach. By applying pressure to this area, it causes satiety without the need for the presence of food. At this time, it is not available for commercial use anywhere but is in preclinical trials.

\section{Conclusion}

Endoscopic approaches to weight loss are gaining popularity. Many technologies are currently being used such as the space filling devices and ESG ( - Fig. 1). Novel approaches to primary bariatric surgery are being developed and are very promising. Some technologies have not withstood the test of time. In general, it appears these endoscopic approaches are here to stay. What is not clear is the expected success and durability of these procedures. There is a gap in therapy between diet/ exercise and surgery for weight loss. These endoscopic procedures can provide an alternative to those patients with Class 1 and 2 obesity. They can even be used for higher class obesity for high-risk patients, those with multiple abdominal surgeries and as a bridge to other weight loss surgery. Currently, these devices are in greater use outside the United States than within it. A large barrier to these procedures in the United States is cost. In the United States and in many countries, these endoscopic approaches are not covered by insurance. Many of these approaches also require expensive devices, general anesthesia, and skilled endoscopists. These requirements are barriers to their widespread use.

What is known is that obesity has reached epidemic proportions worldwide. Level 1 evidence for many of the endoscopic procedures for weight loss is lacking. However, several case series are in the literature and speak to weight loss that is greater than lifestyle changes alone but may be less than surgery with a lower risk profile. Ongoing studies are needed with large numbers and comparative trials.

Another debatable topic with these endoluminal approaches is the definition of success. Should these endoscopic techniques be expected to be as durable and effective as surgery? Or should these approaches be considered another tool in the toolbox for weight loss? Can they be put in a category that allows more pounds lost than programs such as WeightWatchers and Jenny Craig, but less than surgery? These technologies can fit the void between diet/ exercise and surgery. Both SAGES and ASMBS support the development of these procedures and recognize their need in the fight against obesity. ${ }^{39}$

We know obesity is a multidisciplinary disease and multiple approaches need to be available to our patients to be successful. All of these endoscopic approaches should be offered in a comprehensive weight loss program that includes dietary and lifestyle counseling. Adequate behavioral support is also helpful. As the epidemic of obesity grows, endoluminal therapies for metabolic surgery will provide a pivotal role both as primary and metabolic modalities in the bariatric surgeon/ endoscopists armamentarium.

\section{References}

1 Štimac D, Klobučar Majanović S, Ličina M. Recent trends in endoscopic management of obesity. Surg Innov 2016;23(05): 525-537

2 Sullivan S, Edmundowicz SA, Thompson CC. Endoscopic bariatric and metabolic therapies: new and emerging technologies. Gastroenterology 2017;152(07):1791-1801

3 Gaur S, Levy S, Mathus-Vliegen L, Chuttani R. Balancing risk and reward: a critical review of the intragastric balloon for weight loss. Gastrointest Endosc 2015;81(06):1330-1336

4 Genco A, Bruni T, Doldi SB, et al. BioEnterics intragastric balloon: the Italian experience with 2,515 patients. Obes Surg 2005;15 (08):1161-1164

5 Lopez-Nava G, Rubio MA, Prados S, et al. BioEnterics ${ }^{\circledR}$ intragastric balloon $(B I B \circledR)$. Single ambulatory center Spanish experience with 714 consecutive patients treated with one or two consecutive balloons. Obes Surg 2011;21(01):5-9

6 Zerrweck C, Maunoury V, Caiazzo R, et al. Preoperative weight loss with intragastric balloon decreases the risk of significant adverse outcomes of laparoscopic gastric bypass in super-super obese patients. Obes Surg 2012;22(05):777-782

7 Dastis NS, François E, Deviere J, et al. Intragastric balloon for weight loss: results in 100 individuals followed for at least 2.5 years. Endoscopy 2009;41(07):575-580

8 Neto MG, Silva LB, Grecco E, et al. Brazilian Intragastric Balloon Consensus Statement (BIBC): practical guidelines based on 
experience of over 40,000 cases. Surg Obes Relat Dis 2018;14(02): 151-159

9 Ponce J, Woodman G, Swain J, et al; REDUCE Pivotal Trial Investigators The REDUCE pivotal trial: a prospective, randomized controlled pivotal trial of a dual intragastric balloon for the treatment of obesity. Surg Obes Relat Dis 2015;11(04):874-881

10 Carvalho GL, Barros CB, Moraes CE, et al. The use of an improved intragastric balloon technique to reduce weight in pre-obese patients-preliminary results. Obes Surg 2011;21(07):924-927

11 Mion F, Ibrahim M, Marjoux S, et al. Swallowable Obalon ${ }^{\circledR}$ gastric balloons as an aid for weight loss: a pilot feasibility study. Obes Surg 2013;23(05):730-733

12 Trande P, Mussetto A, Mirante VG, et al. Efficacy, tolerance and safety of new intragastric air-filled balloon (Heliosphere BAG) for obesity: the experience of 17 cases. Obes Surg 2010;20(09): 1227-1230

13 Genco A, Ernesti I, Ienca R, et al. Safety and efficacy of a new swallowable intragastric balloon not needing endoscopy: early Italian experience. Obes Surg 2018;28(02):405-409

14 https://www.fda.gov/NewsEvents/Newsroom/FDAInBrief/ ucm609757.htm

15 Tate CM, Geliebter A. Intragastric balloon treatment for obesity: FDA safety updates. Adv Ther 2018;35(01):1-4

16 Ali MR, Moustarah F, Kim JJ; American Society for Metabolic and Bariatric Surgery Clinical Issues Committee. American Society for Metabolic and Bariatric Surgery position statement on intragastric balloon therapy endorsed by the Society of American Gastrointestinal and Endoscopic Surgeons. Surg Obes Relat Dis 2016;12 (03):462-467

17 Huang CS, Farraye FA. Complications following bariatric surgery. Tech Gastrointest Endosc $\cdots \bullet ; 8: 54-56$

18 Tate CM, Geliebter A. Intragastric balloon treatment for obesity: review of recent studies. Adv Ther 2017;34(08):1859-1875

19 Bazerbachi F, Haffar S, Sawas T, et al. Fluid-filled versus gas-filled intragastric balloons as obesity interventions: a network metaanalysis of randomized trials. Obes Surg 2018;28(09):2617-2625

20 Gagner M. Comment on Brazilian Intragastric Balloon Consensus Statement (BIBC): practical recommendations based on experience of over 40,000 cases. Surg Obes Relat Dis 2018;14(02):159-161

21 Lopasso FP, Sakai P, Gazi BM, et al. A pilot study to evaluate the safety, tolerance, and efficacy of a novel stationary antral balloon (SAB) for obesity. J Clin Gastroenterol 2008;42(01):48-53

22 Sauer N, Rösch T, Pezold J, et al. A new endoscopically implantable device (SatiSphere) for treatment of obesity-efficacy, safety, and metabolic effects on glucose, insulin, and GLP-1 levels. Obes Surg 2013;23(11):1727-1733

23 Fogel R, De Fogel J, Bonilla Y, De La Fuente R. Clinical experience of transoral suturing for an endoluminal vertical gastroplasty: 1-year follow-up in 64 patients. Gastrointest Endosc 2008;68(01):51-58

24 Brethauer SA, Chand B, Schauer PR, Thompson CC. Transoral gastric volume reduction for weight management: technique and feasibility in 18 patients. Surg Obes Relat Dis 2010;6(06): 689-694

25 Kumar N, Abu Dayyeh BK, Lopez-Nava Breviere G, et al. Endoscopic sutured gastroplasty: procedure evolution from first-in- man cases through current technique. Surg Endosc 2018;32(04): 2159-2164

26 Sartoretto A, Sui Z, Hill C, et al. Endoscopic Sleeve Gastroplasty (ESG) is a reproducible and effective endoscopic bariatric therapy suitable for widespread clinical adoption: a large, international multicenter study. Obes Surg 2018;28(07):1812-1821

27 Fayad L, Adam A, Dunlap M, et al. Endoscopic sleeve gastroplasty versus laparoscopic sleeve gastrectomy: a case-matched study. Gastrointest Endosc 2018. Doi: 10.1016/j.gie.2018.08.030

28 Familiari P, Costamagna G, Bléro D, et al. Transoral gastroplasty for morbid obesity: a multicenter trial with a 1-year outcome. Gastrointest Endosc 2011;74(06):1248-1258

29 Moreno C, Closset J, Dugardeyn S, et al. Transoral gastroplasty is safe, feasible, and induces significant weight loss in morbidly obese patients: results of the second human pilot study. Endoscopy 2008;40(05):406-413

30 Vilarrasa N, de Gordejuela AG, Casajoana A, et al. Endobarrier ${ }^{\circledR}$ in grade I obese patients with long-standing type 2 diabetes: role of gastrointestinal hormones in glucose metabolism. Obes Surg 2017;27(03):569-577

31 Ellsmere JC, Thompson CC, Brugge WR, et al. Endoscopic interventions for weight loss surgery. Obesity (Silver Spring) 2009;17 (05):929-933

32 Tarnoff M, Rodriguez L, Escalona A, et al. Open label, prospective, randomized controlled trial of an endoscopic duodenal-jejunal bypass sleeve versus low calorie diet for pre-operative weight loss in bariatric surgery. Surg Endosc 2009;23(03):650-656

33 Schouten R, Rijs CS, Bouvy ND, et al. A multicenter, randomized efficacy study of the EndoBarrier Gastrointestinal Liner for presurgical weight loss prior to bariatric surgery. Ann Surg 2010;251 (02):236-243

34 Sandler BJ, Rumbaut R, Swain CP, et al. One-year human experience with a novel endoluminal, endoscopic gastric bypass sleeve for morbid obesity. Surg Endosc 2015;29(11):3298-3303

35 Rajagopalan H, Cherrington AD, Thompson CC, et al. Galvao Neto M. Endoscopic duodenal mucosal resurfacing for the treatment of type 2 diabetes: 6 months interim analysis from the first-inhuman proof-of-concept study. Diabetes Care 2016;39(12): 2254-2261

36 Thompson CC, Abu Dayyeh BK, Kushner R, et al. Percutaneous gastrostomy device for the treatment of class II and class III obesity: results of a randomized controlled trial. Am J Gastroenterol 2017;112(03):447-457

37 Nyström M, Machytka E, Norén E, et al. Aspiration therapy as a tool to treat obesity: 1- to 4-year results in a 201-patient multicenter post-market European Registry Study. Obes Surg 2018;28 (07):1860-1868

38 Machytka E, Buzga M, Ryou M, Lautz DB, Thompson CC. 1139 Endoscopic dual-path enteral anastomosis using self assembling magnets: fist-in-human clinical feasibility. Gastroenterology 2016;150:s232

39 Kurian M, Kroh M, Chand B, Mikami D, Reavis K, Khaitan L. SAGES review of endoscopic and minimally invasive bariatric interventions: a review of endoscopic and non-surgical bariatric interventions. Surg Endosc 2018;32(10):4063-4067 